\title{
METODE HYDRO ENFORCEMENT DATA LIDAR UNTUK PEMBUATAN DIGITAL TERRAIN MODEL OBYEK PERAIRAN PADA PETA RUPA BUMI INDONESIA SKALA 1:5000
}

\author{
Elisya Febriana ${ }^{1}$, Agung Budi Cahyono² \\ ${ }^{123}$ Departemen Teknik Geomatika, FTSLK-ITS, Kampus ITS Sukolilo, Surabaya, 60111, Indonesia \\ e-mail: ㄹelisyafebriana@gmail.com, ㄹagungbc@geodesy.its.ac.id
}

\begin{abstract}
Abstrak
Dalam membuat obyek perairan dari hasil akuisisi LiDAR diperlukan metode untuk membuat permukaan air lebih baik. Salah satu metode pembuatan DTM pada daerah perairan pada pengolahan data LiDAR adalah hydro enforcement. LiDAR (Light Detection and Ranging) merupakan sistem dari Airborne Laser Scanning (ALS). Di Indonesia masih jarang yang menggunakan gelombang hijau dalam pengambilan data LiDAR, sehingga gelombang infra merah menghasilkan nilai elevasi yang terbiaskan karena tidak dapat menembus kedalaman perairan. Dalam pembuatan DTM dibutuhkan kualitas DTM sesuai kontrol kualitas di petunjuk pelaksanaan pembuatan DTM hydro enforcement dari Badan Informasi Geospasial. Pengolahan DTM menggunakan metode hydro enforcement dimulai dari draping terrain badan perairan, menghilangkan mass point dalam perairan hingga pembentukkan breakline untuk badan perairan sesuai hasil draping yang mempunyai interval antar point cloud di badan perairan adalah 0.5 meter. Kemudian melakukan proses macro hydro enforcement pada software pengolahan LiDAR.

Hasil penelitian ini menunjukkan kualitas DTM dengan metode hydro enforcement memberikan visualisasi yang baik untuk perencanaan infrakstruktur dalam pembuatan irigasi, pintu air dan memberikan detail yang baik untuk pembuatan unsur hipsografi dalam Peta RBI skala 1:5000. Namun demikian, metode hydro enforcement ini masih terdapat kekurangan dari segi akurasi, sehingga perlu dilakukan pengambilan data lapangan.
\end{abstract}

Kata kunci : Digital Terrain Model, Hydro Enforcement, Kontrol Kualitas, LiDAR

\section{PENDAHULUAN}

Peta Rupabumi Indonesia (RBI) adalah peta dasar yang memberikan informasi secara khusus untuk wilayah darat. Untuk saat ini skala 1:5000 Badan Informasi Geospasial (BIG) melakukan akuisisi menggunakan foto udara, LiDAR atau airborne radar. LiDAR merupakan salah satu teknologi yang digunakan dalam mempercepat pembuatan peta dasar 1:5000. LiDAR merupakan sistem dari Airborne Laser Scanning (ALS)[1]. Dalam pembuatan Digital Terrain Model (DTM) dari hasil akuisisi LiDAR, pada daerah perairan diperlukan metode khusus yang harus ditambahkan dalam pengolahan data LiDAR. Salah satu metode pembuatan DTM LiDAR adalah hydro enforcement. Metode hydro enforcement merupakan konsep pembentukan DTM dimana air akan mengalir dari tempat tinggi ke tempat rendah)[2]. Unsur hidrografi (sungai, anak sungai, alur) dalam DTM harus mengalir suatu wilayah agar dapat menggambarkan keadaan yang sebenarnya. Pada penelitian ini akan dilakukan analisis DTM dari data LiDAR pada obyek perairan peta RBI skala 1:5000 menggunakan metode hydro enforcement khususnya di daerah Kawasan Ekonomi Khusus (KEK) Tanjung Lesung, Banten.

Kontrol kualitas pada petunjuk pelaksanaan tahapan pembentukan DTM hydro enforcement dari BIG adalah salah satu tahapan dalam pembuatan peta RBI daerah KEK Tanjung Lesung skala 1:5000 agar sesuai dengan prosedur pembuatan peta di BIG. Banyaknya daerah perairan di daerah KEK Tanjung Lesung membuat metode hydro enforcement menjadi salah satu solusi dalam pembuatan DTM pada obyek perairan.

\section{METODE}

\section{A. Lokasi Penelitian}

Data LiDAR dalam penelitian ini berlokasi di KEK Tanjung Lesung, Provinsi Banten dengan koordinat $6^{\circ} 31^{\prime} 27.5^{\prime \prime} \mathrm{LS}-6^{\circ} 31^{\prime} 48.7^{\prime \prime} \mathrm{LS}$ dan $105^{\circ} 41^{\prime} 32.0^{\prime \prime} \mathrm{BT}$ $105^{\circ} 43^{\prime} 38.4^{\prime \prime} \mathrm{BT}$. 


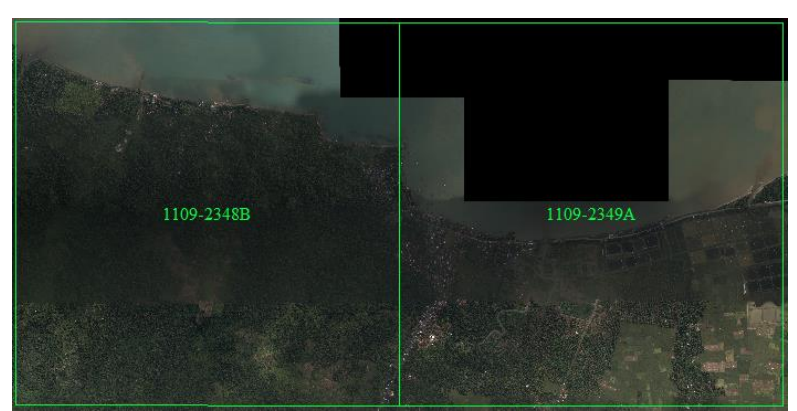

Gambar 1. Lokasi penelitian KEK Tanjung Lesung NLP 1109-2348B dan 1109-2349A

\section{B. Data dan Peralatan}

a. Data

Data yang digunakan dalam penelitian ini yaitu meliputi berikut:

1. Data digitasi foto udara 2D KEK Tanjung Lesung, Banten NLP 1109-2348B dan 11092349A tahun 2017

2. Data foto udara KEK Tanjung Lesung, Banten NLP 1109-2348B dan 1109-2349A tahun 2017

3. Data Digital Terrain Model LiDAR KEK Tanjung Lesung, Banten NLP 1109-2348B dan 1109-2349A tahun 2017

4. Peta Rupabumi Indonesia 1:25000 lembar 1109-234 Cigeulis tahun 1998

\section{b. Peralatan}

Peralatan yang digunakan dalam penelitian ini yaitu :

1. Perangkat Keras

Komputer Laptop Acer Aspire 4743 Core $^{\mathrm{TM}}$ i3-380mM $(2.1 \mathrm{GHz})$ dengan RAM 6, HD $500 \mathrm{Mb}$.

2. Perangkat Lunak

i. Software pengolah data spasial

ii. Software pengolah data LiDAR

\section{Tahap Pengolahan Data}

Tahapan pengolahan data yang dilaksanakan dalam penelitian ini adalah sebagai berikut:

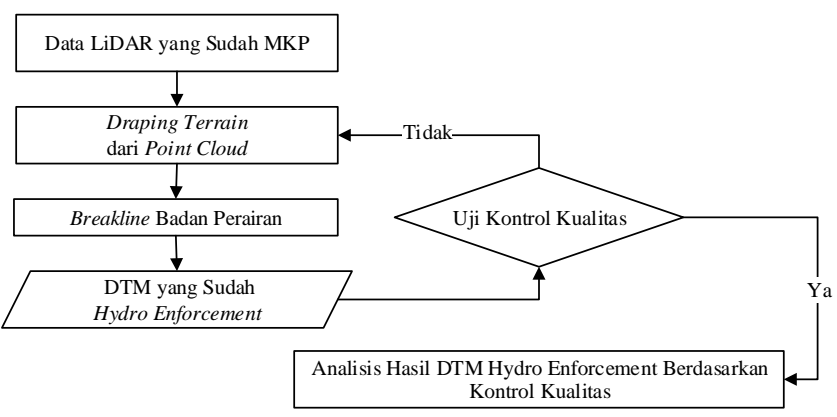

Gambar 2. Diagram Alir Pengolahan Data
Dalam pengolahan data dibutuhkan data LiDAR yang sudah di Model Key Point (MKP) supaya data LiDAR menjadi ringan untuk diolah. Tahap pertama melakukan draping pada hasil awal terrain elevation grid dari Data LiDAR yang sudah di MKP untuk mendapatkan data elevasi untuk mengetahui arah aliran perairan. Hasil draping tersebut dijadikan bahan untuk pembuatan breakline yang mempunyai interval antar point cloud 0.5 meter pada badan perairan yang kemudian di proses di software pengolahan LiDAR untuk menghilangkan mass point yang ada di daerah perairan dan pembuatan breakline tersebut. Hasil DTM yang sudah di lakukan metode hydro enforcement diuji kesesuaiannya sesuai kontrol kualitas.

Tabel 2. Penilaian Kualitas DTM

\begin{tabular}{|c|c|}
\hline NO & Parameter Kontrol Kualitas \\
\hline 1 & Tidak ada mass point di dalam perairan. \\
\hline 2 & $\begin{array}{l}\text { Bentukan sesuai dengan breakline dan } \\
\text { perairan }\end{array}$ \\
\hline 3 & $\begin{array}{l}\text { Kehalusan DTM konsisten dan tidak } \\
\text { membentuk undakan }\end{array}$ \\
\hline 4 & $\begin{array}{l}\text { Tidak ada ketinggian dibawah } 0 \text { meter kecuali } \\
\text { depresi atau cekungan }\end{array}$ \\
\hline 5 & $\begin{array}{l}\text { Cekungan (depressions) dan terasering } \\
\text { dengan perbedaan tinggi lebih dari } 1 \text { meter } \\
\text { terbentuk }\end{array}$ \\
\hline 6 & $\begin{array}{l}\text { Tidak ada nilai ketinggian yang ekstrim } \\
\text { (spikes) }\end{array}$ \\
\hline 7 & Tubuh air mempunyai ketinggian yang sama. \\
\hline 8 & $\begin{array}{l}\text { DTM di sepanjang arah aliran air (sungai, } \\
\text { alur) mengalir secara smooth. }\end{array}$ \\
\hline 9 & Profil melintang DTM Halus dan logis \\
\hline 10 & $\begin{array}{l}\text { Kesesuaian dengan NLP (Nomor Lembar Peta) } \\
\text { yang bersebelahan. }\end{array}$ \\
\hline
\end{tabular}

(Sumber: Badan Informasi Geospasial 2016)

\section{HASIL DAN PEMBAHASAN}

\section{A. Data LiDAR}

Tahap awal sebelum melakukan proses pengolahan data LiDAR menggunakan metode hydro enforcement untuk daerah perairan adalah menyiapkan data LiDAR yang telah di Model Key Point (MKP). Pembuatan Model Key Point (MKP) digunakan sebagai data masukan awal untuk melakukan klasifikasi point pada pemrosesan hydro enforcement. MKP adalah perwakilan point cloud 
ground. MKP dapat dibuat berdasarkan sampling point berdasarkan interval jarak atau jumlah point.

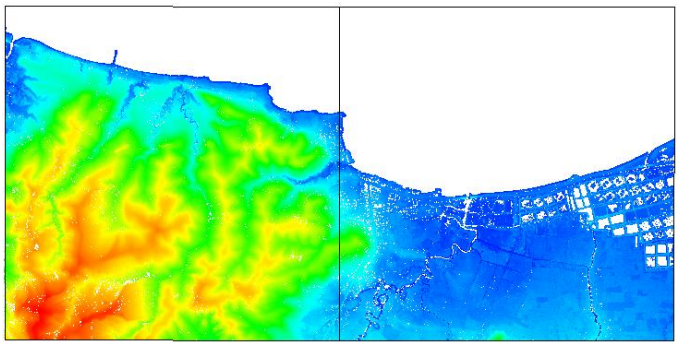

Gambar 3. NLP 1109-2348B dan 1109-2349A yang Telah di MKP dan Klasifikasi Ground

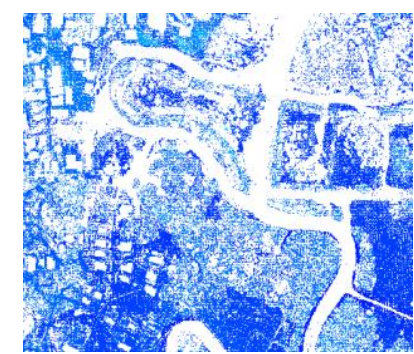

Gambar 4. Contoh Point Cloud Daerah Perairan

Terlihat dari bentuk sungai pada gambar di atas, masih banyak mass point yang terdapat di daerah perairan yang membuat bentuk topografi sungai tidak seperti sungai yang harusnya mengalir dari hulu ke hilir.

\section{B. Draping Terrain dari Point Cloud}

Dalam draping ketinggian point cloud ini menjadi acuan untuk perairan tersebut akan mengalir. Draping dilakukan pada terrain elevation grid point cloud LiDAR yang mempunyai ketinggian. Dalam melakukan draping diperlukan ketelitian untuk menentukan tinggi point cloud muka air. Dalam menentukan ketinggian genangan, rawa, kolam, laut, peraitan sawah dikategorikan perairan yang tidak mengalir, maka ketinggiannya di jadikan 0 meter karena tidak mengalir dianggap datar. Hasil draping ini digunakan sebagai acuan ketinggian untuk pembentukan breakline dalam pembuatan badan perairan. Dari hasil digitasi 2D dihasilkan 21 sungai besar, 42 sungai kecil dan 4 daerah yang dianggap tergenang (flattern).

\section{Klasifikasi Point dalam Perairan}

Mass point adalah titik tinggi pada permukaan tanah yang bukan termasuk spotheigth (titik tinggi pada puncak gunung atau bukit dan pada cekungan di permukaan tanah). Tidak ada mass point yang berada di dalam perairan[4]. Klasifikasi point LiDAR dari class default ke low point untuk point cloud yang berada didalam digitasi perairan. Untuk klasifikasi ini menggunakan macro by classify di software pengolahan LiDAR.

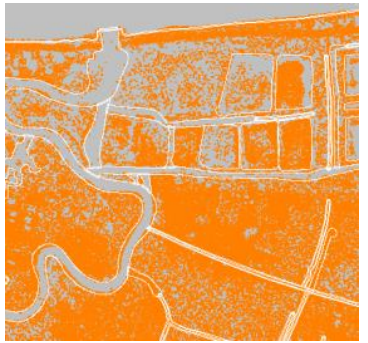

(a)

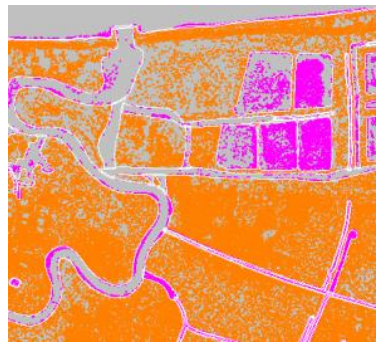

(b)
Gambar. 5. (a) Sebelum Klasifikasi dari Ground Point ke Low Point, (b) Sesudah Klasifikasi dari Ground Point ke Low Point

Dari hasil klasifikasi tersebut terdapat 46.972 dari 3.644.766 points di NLP 1109-2348B.las dan terdapat 232.751 dari 3.009.222 points di NLP 11092349A.las yang berhasil diklasifikasikan ke dalam low point. Sudah terlihat dari warna yang berbeda, untuk ground berwarna orange dan untuk yang diklasifikasikan ke dalam perairan berwarna ungu. Sudah terlihat dari warna yang berbeda, untuk ground berwarna orange dan untuk yang diklasifikasikan ke dalam perairan berwarna ungu.

\section{Breakline Badan Perairan}

Breakline ditambahkan dalam DTM yang telah diproses untuk membentuk terrain sesuai dengan kondisi lapangan. Unsur breakline yang digunakan adalah unsur hidrografi sungai dua garis dan unsur air yang datar menempati ruang seperti rawa dan danau[5]. Pembuatan breakline mengikuti garis digitasi badan perairan. Pada tahap breakline ini dimasukkan nilai elevasi awal dan akhir dari masingmasing sungai pada saat draping. Nilai elevasi tersebut menentukan arah aliran air sungai. Memiliki kerapatan antar point cloud dibadan perairan adalah 0.5 meter.

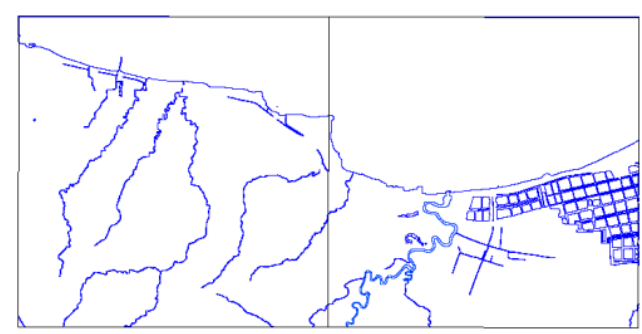

Gambar 6. Hasil Breakline Daerah Perairan 


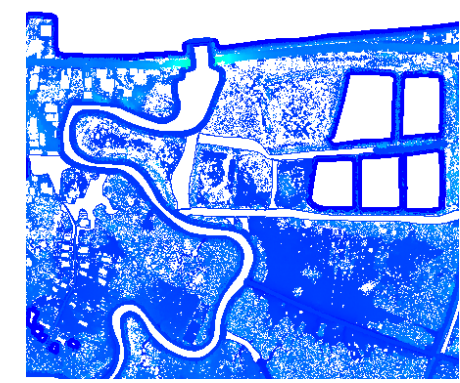

Gambar 7. Hasil Breakline Salah Satu Daerah

Perairan dengan Point Cloud Sekitarnya

\section{E. Run Macro Hydro Enforcement}

Run Macro pada perangkat lunak pengolahan LiDAR adalah proses akhir untuk pembuatan DTM dengan metode hydro enforcement. Dengan mengklasifikasikan point cloud yang ada di perairan dari ground point ke low point. Kemudian, menambahkan point perairan hasil breakline yang akan merepresentasikan muka perairan dapat dikenali dengan baik dalam pembentukkan DTM.

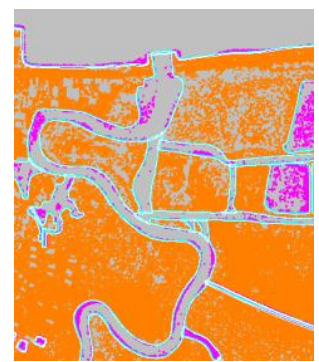

Sebelum

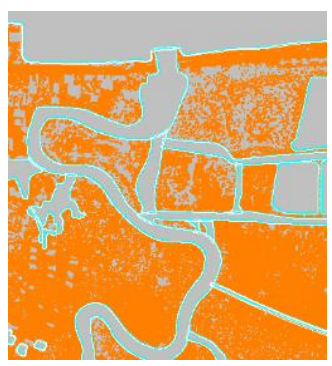

Sesudah
Gambar 8. Hasil Run Macro Hydro Enforcement

Ada tambahan warna pada gambar diatas, yaitu biru muda menandakan breakline perairan sudah masuk menjadi point cloud. Setelah itu jadikan output baru dengan format .las untuk melihat bentukan DTM setelah dilakukan macro hydro enforcement.

\section{F. Visualisasi Path Profile}

Path profile adalah salah satu tool untuk mengetahui tinggi permukaan perairan tersebut apakah sudah mengalir atau belum. Dan dapat mengetahui elevasi dari permukaan perairan tersebut. Sebelumnya hasil output dari setelah macro tadi buat elevation grid dengan metode triangulasi (Grid TIN of Points).

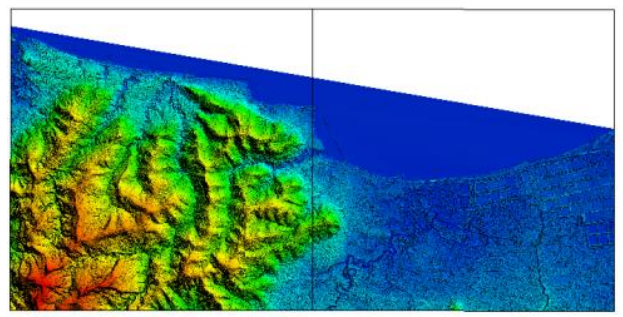

Gambar 9. Hasil DTM Sebelum Menggunakan Metode Hydro Enforcement

Setelah terbentuk Digital Terrain Model (DTM) baru bisa digunakan tool path profile untuk mengetahui profiling secara melintang atau memanjang di daerah perairan.

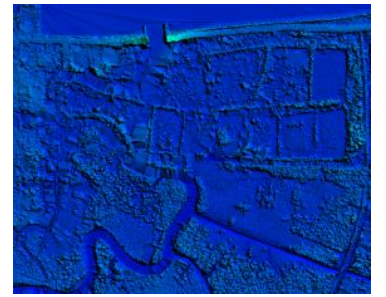

Sebelum

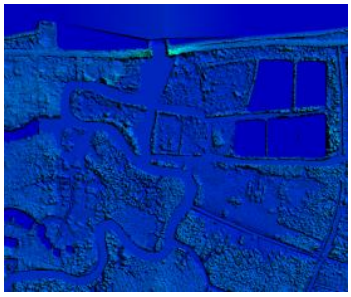

Sesudah
Gambar 10. Hasil Sebelum Pembentukkan DTM Menggunakan Metode Hydro Enforcement

Dari path profile pada gambar diatas dapat disimpulkan jika secara memanjang mengikuti aliran sungai sebelum menggunakan metode hydro enforcement memiliki tinggi elevasi yang signifikan berubah dan dengan begitu tidak tahu arah aliran sungai tersebut kemana. Terjadi perbedaan tinggi yang sangat berbeda dan bisa dikatakan itu noise yang seharusnya dihilangkan. Daerah perairan terlihat lebih halus dan dapat dikenali dengan baik. Metode hydro enforcement membantu untuk penyempurnaan topografi di bagian perairan yang paling mendekati sesuai dengan kenampakan sebenarnya. Pada hasil path profile setelah menggunakan metode hydro enforcement mengalami penururan sungai yang mengalir dengan konstan dan mengetahui arah aliran air tersebut dilihat dari elevasinya. Dengan perbedaan 0.01 meter membuat aliran sungai mengalir secara halus. Dan ketinggian 0 meter berlaku pada tambak, kolam dan area lainnya yang tergenang. 


\section{G. Hasil Uji Kontrol Kualitas DTM}

Tabel 3. Hasil Penilaian Kualitas DTM

\begin{tabular}{|c|c|c|c|}
\hline $\begin{array}{c}\text { Penilaian Kualitas } \\
\text { DTM }\end{array}$ & Sesuai & Tidak & Nihil \\
\hline $\begin{array}{l}\text { Tidak ada masspoint } \\
\text { di dalam perairan }\end{array}$ & $\checkmark$ & & \\
\hline $\begin{array}{l}\text { bentukan sesuai } \\
\text { dengan breakline dan } \\
\text { perairan }\end{array}$ & $\checkmark$ & & \\
\hline $\begin{array}{l}\text { Kehalusan DTM } \\
\text { konsisten dan tidak } \\
\text { membentuk undakan }\end{array}$ & $\checkmark$ & & \\
\hline $\begin{array}{l}\text { Tidak ada ketinggian } \\
\text { dibawah } 0 \text { kecuali } \\
\text { depresi atau } \\
\text { cekungan }\end{array}$ & $\checkmark$ & & \\
\hline $\begin{array}{l}\text { Cekungan } \\
\text { (depressions) dan } \\
\text { terasering dengan } \\
\text { perbedaan tinggi lebih } \\
\text { dari } 1 \mathrm{~m} \text { terbentuk }\end{array}$ & & & $\checkmark$ \\
\hline $\begin{array}{l}\text { Tidak ada nilai } \\
\text { ketinggian yang } \\
\text { ekstrim (spikes) } \\
\end{array}$ & & & $\checkmark$ \\
\hline $\begin{array}{l}\text { Tubuh air tergenang } \\
\text { mempunyai } \\
\text { ketinggian sama }\end{array}$ & $\checkmark$ & & \\
\hline $\begin{array}{l}\text { DTM di sepanjang } \\
\text { arah aliran air (sungai, } \\
\text { alur) mengalir secara } \\
\text { smooth }\end{array}$ & $\checkmark$ & & \\
\hline $\begin{array}{l}\text { Profil melintang DTM } \\
\text { halus dan logis }\end{array}$ & $\checkmark$ & & \\
\hline $\begin{array}{l}\text { Kesesuaian dengan } \\
\text { NLP yang } \\
\text { bersebelahan } \\
\text { (topografi, kehalusan) }\end{array}$ & $\checkmark$ & & \\
\hline
\end{tabular}

\section{H. Proses Aplikasi Metode Hydro Enforcement}

Mulai dari proses draping, membuat jadi flattern atau mengosokan mass point yang berada di daerah perairan kemudian pembuatan breakline untuk badan perairan pada tahapan pembuatan DTM dengan menggunakan metode hydro enforcement ini dapat dikatakan sesuai interpretasi masing-masing operator yang mengolah. Dan kesalahan draping dapat membuat ketidaksesuaian terhadap badan perairan tersebut terlihat berbeda jika sudah dijadikan DTM. Proses metode hydro enforcement ini hanya dapat diuji sesuai kualitas DTM nya menurut petunjuk pelaksanaan yang diberikan oleh Badan Informasi Geospasial. Secara kuantitas nilai elevasi pada badan sungai tidak dapat dijadikan referensi yang akurat.

\section{KESIMPULAN}

1. Telah dibuat Digital Terrain Model (DTM) pada daerah KEK Tanjung Lesung, Provinsi Banten NLP 1109-2348B dan 1109-2349A dari data LiDAR dengan metode hydro enforcement yang terdiri dari 21 sungai besar, 42 sungai kecil dan 4 daerah genangan.

2. Hasil uji kualitas DTM menunjukkan, dari 10 parameter kontrol kualitas petunjuk pelaksanaan metode hydro enforcement, terdapat 8 parameter yang sesuai dengan kualitas parameter yang ada, 2 parameter tidak sesuai karena memang tidak ada pada daerah yang dianalisis untuk parameter itu, yaitu cekungan (depressions) dan terasering dengan perbedaan tinggi lebih dari 1 meter terbentuk serta tidak ada nilai ketinggian yang ekstrim (spikes).

3. Kelebihan hasil DTM dengan metode hydro enforcement ini memberikan visualisasi yang baik berdasarkan uji kualitas DTM yang sesuai dan detail terrain yang jelas dalam resolusi tinggi untuk perencanaan infrakstruktur, pembuatan irigasi, pintu air dan memberikan detail yang baik dan jelas untuk pembuatan unsur hipsografi dalam Peta RBI skala 1:5000.

4. Metode hydro enforcement ini masih terdapat kekurangan dari akurasinya, karena uji kuantitasnya hanya saat post processing data LiDAR sebelum masuk proses klasifikasi manual data LiDAR.

\section{UCAPAN TERIMA KASIH}

Penulis mengucapkan terima kasih kepada Badan Informasi Geospasial dan PT. Waindo Specterra yang telah menyediakan data foto udara dan LiDAR daerah KEK Tanjung Lesung, Banten.

\section{DAFTAR PUSTAKA}

Arfaini, J., (2016). Pembuatan DEM (Digital Elevation Model) Menggunakan Metode Tin, IDW, dan Kriging dari Data Foto Udara. Surabaya: Institut Teknologi Sepuluh Nopember. 
Badan Informasi Geospasial. (2016). Petunjuk Pelaksanaan Tahapan Hydro Enforcement. Pusat Pemetaan Rupabumi dan Toponim.

Badan Informasi Geospasial. (2017). Kerangka Acuan Kerja Pembuatan Unsur Peta Rupabumi Indonesia Skala 1:5000. Pusat Pemetaan Rupabumi dan Toponim.

Badan Informasi Geospasial. (2017). Petunjuk Pelaksanaan Tahapan Pengolahan Data LiDAR. Pusat Pemetaan Rupabumi dan Toponim.Badan Informasi Geospasial.

Putri, M.D., (2016). Pemodelan Tigas Dimensi Daerah Pesisir Dengan Menggunakan Data LiDAR dan Ortofoto. Yogyakarta: Universitas Gajah Mada.

Wehr, A., and Lohr, U. 1999, "Airborne laser scanning-an introduction and overview", ISPRS Jurnal of Photogrametry and Remote Sensing, Vol.54, hal 68-82. 